Western University

Scholarship@Western

Western Libraries Publications

Western Libraries

$12-22-2015$

\title{
Collaborative Approaches to the Management of Geospatial Data Collections in Canadian Academic Libraries: A Historical Case Study
}

Leanne Trimble

University of Toronto

Cheryl Woods

Western University, cawoods@uwo.ca

Francine Berish

Queens University

Daniel Jakubek

Ryerson University

Sarah Simpkin

University of Ottawa

Follow this and additional works at: https://ir.lib.uwo.ca/wlpub

Part of the Geographic Information Sciences Commons, and the Library and Information Science Commons

Citation of this paper:

Trimble, Leanne; Woods, Cheryl; Berish, Francine; Jakubek, Daniel; and Simpkin, Sarah, "Collaborative Approaches to the Management of Geospatial Data Collections in Canadian Academic Libraries: A Historical Case Study" (2015). Western Libraries Publications. 47.

https://ir.lib.uwo.ca/wlpub/47 


\title{
Collaborative Approaches to the Management of Geospatial Data Collections in Canadian Academic Libraries: A Historical Case Study
}

\author{
Leanne Trimble University of Toronto, Toronto, Ontario, Canada \\ Cheryl Woods Western University, London, Ontario, Canada \\ Francine Berish Queen's University, Kingston, Ontario, Canada \\ Daniel Jakubek Ryerson University, Toronto, Ontario, Canada \\ Sarah Simpkin University of Ottawa, Ottawa, Ontario, Canada
}

\begin{abstract}
The Ontario Council of University Libraries (OCUL) is a consortium of the twenty-one university libraries in Ontario, Canada. Since 1967, OCUL member institutions have worked together to share costs and workload through collective purchasing/licensing of information resources, and more recently through the establishment of a shared digital infrastructure known as Scholars Portal. Under the auspices of OCUL, Ontario's university map librarians formed the OCUL Map Group in 1973 to seek opportunities to communicate and collaborate to improve the collections and services they could offer to their users. The opportunities provided by collaboration have ensured a greater capacity to manage evolving collections of geospatial data. The group has served as a community of practice, which has provided educational opportunities and facilitated collaborative problem-solving through a listserv, conference calls and face-to-face meetings. This collegial environment has also led to the completion of a number of projects, which have resulted in the creation of new technical infrastructures and strategies for sharing the workload on data management tasks. This paper discusses the role of collaboration in OCUL projects, and offers some suggestions for others considering embarking on collaborations of their own.
\end{abstract}

Keywords: GIS libraries, library consortia, collaboration, map collections, geospatial data collections, geospatial data portals, map digitization

\section{Introduction}

The Ontario Council of University Libraries (OCUL) is a consortium of the twenty-one university libraries in Ontario, Canada. Since its founding in 1967, OCUL member libraries have worked together on a wide range of projects and activities. Early initiatives were focused on supporting improved interlibrary loan systems, and on the cooperative cataloguing and inventorying of collections. As e-resources came to prominence in the 1990s, OCUL became involved in negotiating consortial licenses for electronic journals and databases. In 2002, a shared technology infrastructure program, known as Scholars Portal, was established. Scholars Portal provides storage and electronic access to OCUL-licensed electronic resources, supports an Ontario-wide interlibrary loan system, and offers a range of other programs and services including chat reference, an OpenURL link resolver, collection analysis tools, and others. ${ }^{1}$ 


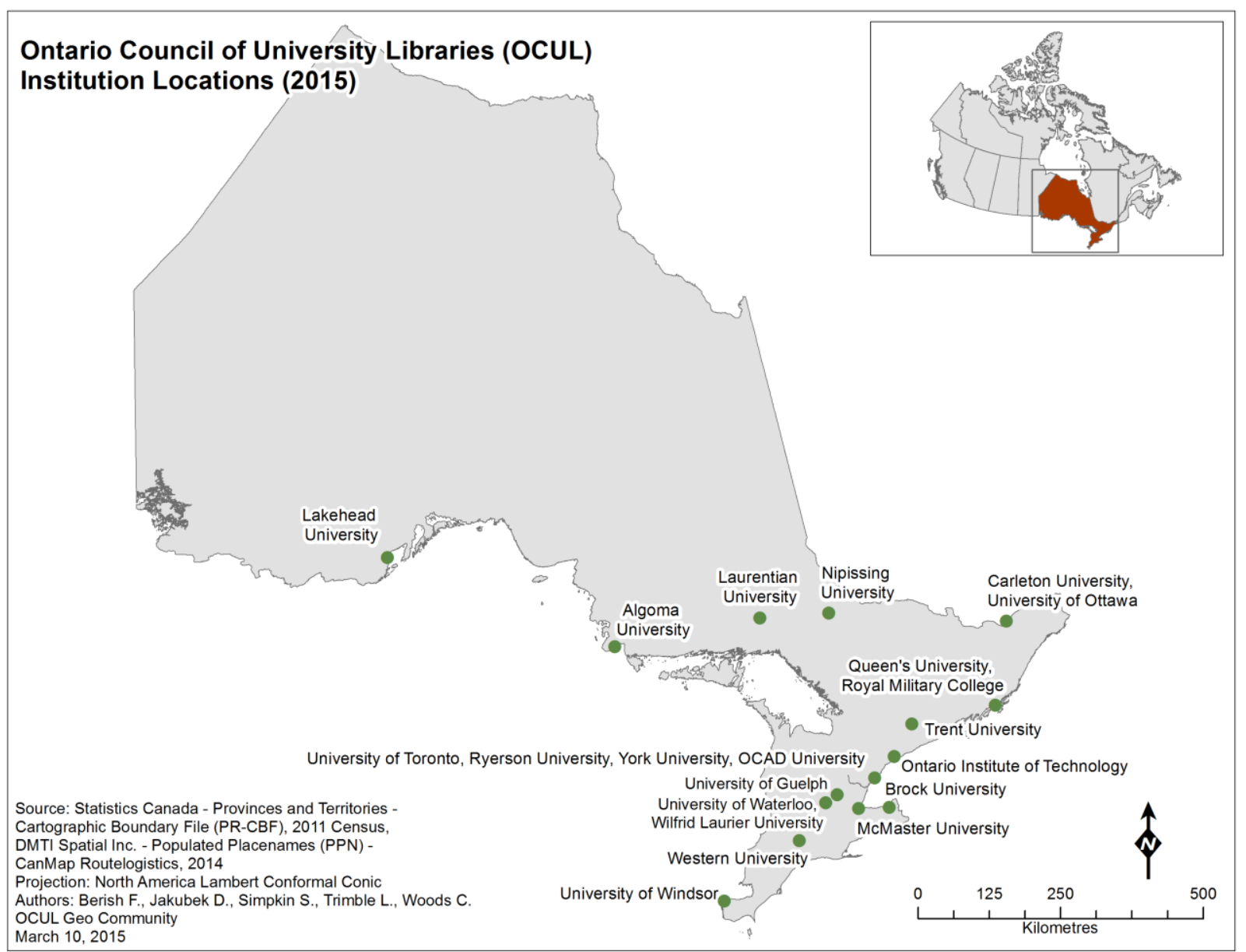

Figure 1. OCUL's twenty-one member institutions

In addition to these activities, OCUL has played a role in encouraging professional development and collaboration among the staff at member libraries. Ontario's university map librarians formed the OCUL Map Group in 1973, becoming the first subject specialist group to formally organize under the auspices of OCUL. For more than forty years OCUL Map Group members have sought opportunities to cooperate and collaborate, and these activities have been instrumental in their ability to continually improve collections and services. In this paper, we offer the story of the OCUL Map Group (today called the OCUL Geo Community) as a case study of the power of collaboration. The specific initiatives described represent ways of solving, or at least mitigating, some of the common challenges faced by map/GIS libraries - challenges which are often much less daunting when faced in collaboration with colleagues.

\section{The Role of Collaboration}

There is little doubt that collaboration can be a powerful tool for achieving challenging objectives. Rebecca Gajda has argued that "most intentional, inter-organizational collaboratives (i.e., strategic alliances) articulate the collaborative effort as the primary method for achieving ideal short and/or long-term goals that would not otherwise be attainable as entities working independently" (Gajda 2004, 65). However, it is not always clear exactly what is meant by the 
term collaboration. A range of terminology is used to describe both collaboration itself (from "working together" to "teamwork" to "cooperation") and the kinds of relationships that constitute collaborations (from "associations" to "coalitions" to "consortiums"). In attempting to more precisely define collaboration, we tend to arrive at a continuum of interactions, beginning with cooperation ("independent groups share information that supports each other's organizational outcomes"), moving to coordination ("independent parties align activities or co-sponsor events or services that support mutually beneficial goals"), and culminating in collaboration ("individual entities give up some degree of independence in an effort to realize a shared goal") (Gajda 2004, 68-9).

Libraries have a long history of working together throughout the continuum from cooperation to collaboration, and have often turned to consortia as the structure for their shared activities. While libraries have been cooperating with one another since the nineteenth century, and formal library consortia have existed since at least the 1930s, the formation of consortia took off in the 1960s, with more than 100 library consortia forming in the United States (U.S.) in that decade (Nfila and Kwasi 2002, 204). Library consortia have traditionally been engaged in cooperative projects to share resources (e.g., interlibrary loan) and to leverage greater buying power when licensing information resources. In this, OCUL is no different: among its early projects were an interlibrary loan system and a cooperative cataloguing service, and by the 1990s OCUL was heavily engaged in consortial purchases of electronic resources.

As information resources moved to the digital environment (including the explosion of digital geospatial data), with new pricing, storage, and distribution requirements, libraries have increasingly struggled to fund and manage the resources their users require. The rationale for working together has become ever more compelling. The situation has become even starker since the economic crisis of 2008, after which library budgets have declined significantly. In 2012, the Online Computer Library Center (OCLC), undertook a study asking roughly 100 leaders of U.S. library consortia about their strategic initiatives, their communication methods and their groups' biggest challenges (OCLC 2013). Funding was identified as the biggest challenge, representing over half of responses. Given these challenges, it is not surprising that facilitating resource sharing, and increasing efficiencies and leadership through collaboration represent the chief mission of surveyed consortia (OCLC 2013, 2). The top three future initiatives of library consortia include the licensing of e-content, improved resource sharing and digital projects (OCLC 2013, 3). In Ontario, OCUL's strategy to collectively purchase and license content that can be shared within and beyond the consortia through digital projects reflects the similarities between Canadian and U.S. consortia.

These traditional, but still vital, consortial roles are at the cooperation or coordination stage in the continuum of interactions. However, financial challenges are not the only obstacles that libraries are struggling to overcome. Changes in technology, teaching, and scholarly research and communication have altered the types of services that users require from the academic library. Kaufman has argued that as libraries attempt to define their role within the university in the 21st century, "greater engagement and... deeper, richer, and more integrative collaborative ventures" are needed in order to offer new services that are more integrated within the institution (Kaufman 2012, 55). OCUL has recognized this imperative and in 2014 embarked on a project that is being referred to as "Collaborative Futures". 2 The project will involve exploring opportunities for transforming the way libraries work together in order to achieve true collaborations.

Throughout the decades of OCUL's existence, the OCUL Map Group has been an active subgroup whose activities have in many ways paralleled those of its parent organization, and in some cases driven OCUL's activities in important new directions. The OCLC study identified professional networking as an important benefit of consortia membership, and this benefit has been realized through the OCUL Map Group $(2013,2)$. By providing specialized library staff the opportunity to communicate with one another regularly, it has been possible to identify service 
gaps and opportunities for collaboration that might not have been otherwise recognized. Supporting geospatial data can be a resource-intensive library service. The activities of the OCUL Map Group clearly demonstrate the kinds of challenges that can be overcome by working together.

\section{Origins of the OCUL Map Group}

The formation of the OCUL Map Group fits not only within the history of the development of library consortia, but also within the history of map librarianship as a profession. Many map libraries were established within universities in the decades post-WWII in response to an increased interest in maps and geography sparked by the war (Ristow 1980,18). This period of growth was also a period of uncertainty, with few formal training opportunities or guidelines available for the operation of a map library. Librarians naturally turned to one another for support. During this time a number of professional associations for map libraries were launched, including the Special Libraries Association's Geography and Map Division in 1944, the Association for Canadian Map Libraries and Archives (ACMLA) in 1967, the Western Association of Map Librarians (WAML), also in 1967, and the American Library Association's Map and Geography Round Table (MAGERT, now MAGIRT or the Map and Geospatial Information Round Table) in 1979 (Weimer 2011, 2). Map cataloguing was gradually integrated into standard cataloguing rules, and librarians produced practical guides to all aspects of their work. Helen Wallis remarked that:

whatever his background, the new recruit to map librarianship in the late 1970s can be assured of one thing; he enters a well-knit international community of map librarians and of others concerned in one way or another with maps. Many interests and disciplines are united when people come together in the pursuit of cartographic enlightenment and in the service of an increasingly map-minded public. Many friendships have been made to bind together this community of kindred spirits (1979, p.116).

This was the context for the formation of the OCUL Map Group in 1973 (originally called the "Map Project Group"). The affiliation with OCUL provided opportunities to engage in practical consortial projects, but the Map Group has also served as an important venue for professional development and networking among a group of libraries which, while diverse in many ways, shared common experiences.

The Chief Librarian/Library Director of each OCUL institution nominated one full member to the group; other interested parties could become associate members. One Chief Librarian/Library Director was appointed as a liaison who would report to OCUL on behalf of the Map Group to facilitate communication between the bodies. The members elected a chairman of the Group and he/she reported the Group's activities to that Chief Librarian/Library Director. The OCUL Map Group's early objectives included:

1. the provision of improved information services to map users;

2. the rationalization of map collections to avoid unnecessary duplication;

3. a greater sharing of map resources; and

4. the cooperative exchange of ideas and information between members in order to explore ways to integrate map collections in Ontario universities into their parent library systems of documentation and control. 
Representatives from the universities of Guelph, McMaster, Queen's, Waterloo, Western Ontario and York participated in the first meeting. The Map Group agreed to work on projects that would be beneficial to all map collections in Ontario universities, and which might, ultimately, meld with similar projects in other provinces. Early activities included: a union lists of atlases and topographic series, a directory of sources for thematic maps, an Interlibrary Loan (ILL) service for maps, and the Map Exchange, a program for institutions to distribute their duplicate maps to other libraries.

At the time the group was formed, map collections held at member institutions were not necessarily catalogued or housed within their university library collections. The Union List of Atlases included these errant materials, providing access to materials that were otherwise challenging to locate. Likewise, the Union List of Topographic Series, released in 1977, fulfilled a similar need for locating topographic maps that were not easy to locate by particular geographical area or time period. For example, few institutions had topographic map coverage of Ghana at 1:50,000, nor the reproduction topographic map coverage of England and Wales at $1: 63,360$ dated 1895.

With the publication of these union lists, demand for interlibrary loan services grew significantly. However, maps were not available to libraries through the existing ILL channels. In response, Map Group members worked to formalize ILL procedures, producing a handbook detailing the loan rules and "best practices" for the ILL of their cartographic collections. These included circulation guidelines for maps, atlases, and aerial photographs, or air photos. In addition to the loaning of maps, the OCUL Map Group also implemented the Map Exchange Program, which involved the circulation of boxes of duplicate and out-of-print maps to university map collections throughout Ontario. The Inter-University Transit System, which transported ILL material, agreed to accept larger sized boxes in order to accommodate the activities of the Map Exchange. Many collections, especially the new and small collections, obtained maps not otherwise available to them through this initiative.

The Map Sources Directory, published in 1978, filled a great need within the map library community as very few thematic maps published were advertised. Acquisition of such material was extremely difficult and time-consuming before this list was available. Canadian map publishers were not easy to find and word-of-mouth was often how the maps became known. These small companies produced short print runs of the maps and websites for advertising was not an option in the 1970s. The Canadian government publication of thematic maps was irregular and usually comprised of a set of maps, not a single sheet. The Map Sources Directory brought together the combined knowledge of the OCUL Map Group members in this area.

In the early years, the OCUL Map Group shared the acquisitions responsibilities for Ontariowide map collections, and worked closely with provincial government departments to devise consortial fee models and distribution methods. Many of the thematic map sets for Ontario were published by a number of provincial government departments, first in paper and later in digital format. Some of those paper maps included: Forest Inventory at 1:15,840; Township Artificial Drainage Systems at 1:25,000; Hazard Land Mapping at 1:15,840; Township Agricultural Land Use at 1:50,000; county soil maps at various scales; and Susceptibility of Ground Water to Contamination at 1:50,000. 


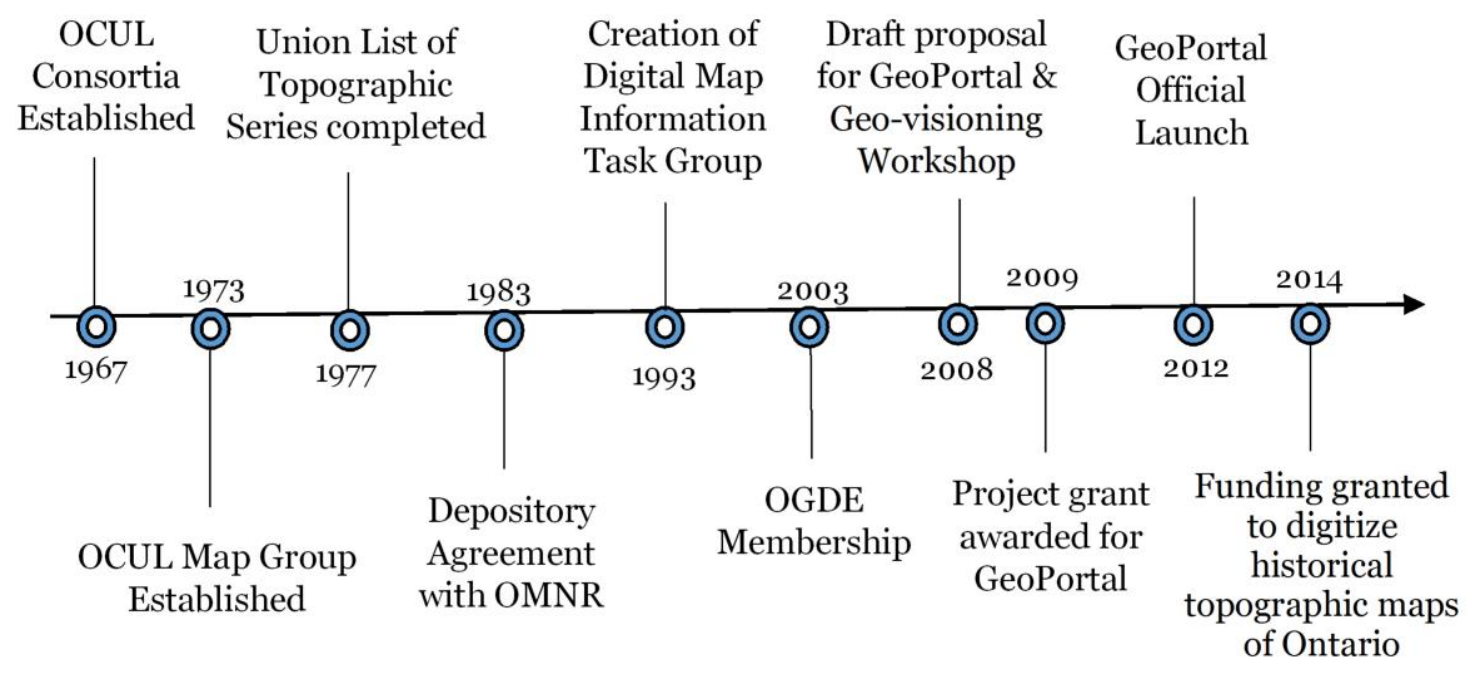

Figure 2. Timeline of major OCUL Map Group projects

\section{Collaborative Projects to meet Evolving Needs}

As GIS technology and geospatial data rose to prominence in the 1990s, the OCUL Map Group evolved along with its members, who began to share their experiences in acquiring and managing new types of collections and software, as well as learning new techniques and technologies. This was a period of great change in map libraries. Many major government map producers became less committed to producing printed copies of their products, and libraries experienced increased demand for access to digital maps and geospatial data (Millea 2001, 3033). Libraries suddenly had a range of new challenges to meet, since these emerging formats could be very expensive to license, required significant amounts of digital storage space, and required specialized knowledge to utilize. In many cases map libraries reacted hesitantly at first, and

"tended to purchase modestly but practically, selectively acquiring data on CD-ROM or disk... Such items function in a manner familiar to librarians - they can be catalogued and used as substitutes for paper maps, and perhaps of greatest relevance, their natural home is the map library, not the computing laboratory" (Millea 2001, 36).

In Ontario, collaboration gave map libraries confidence, and there was a clear recognition of the value of fully embracing emerging file formats, alternative methods of data distribution, and new technologies. It was in this period that the group embarked on the first of our example projects, consortial data licensing and acquisition, discussed in more detail below.

Around this time, another Ontario group was formed to facilitate further collaboration related to map libraries: specialized library staff formed their own group known as the Map Library Assistants group. This group corresponds over a listserv, which is open only to map library assistants working for OCUL institutions, and provides a forum for members to share information and discuss issues relevant to their interests. Map Library Assistants workshops have been held every other year since 2003 , with the following goals:

1. To provide an opportunity for Map Library Assistants to meet and establish a network of contacts with their counterparts and colleagues in other Ontario universities; 
2. To provide an opportunity for Map Library Assistants to visit another Ontario university map collection to compare and share procedures and practices of common interest.

3. To provide educational sessions, training and information relevant to the rapidly changing field of geographic information management, specifically aimed at Map Library Assistants' needs.

The workshop is intended for map library assistants working in OCUL Map Group member institutions, and for any other library support staff who deal with geographic information. Job title is not important, as not every institution uses the description "library assistant" - any support staff member who works with geographic information, in any capacity, is welcome. The session is not, however, intended for map librarians, who have educational and networking opportunities through the OCUL Map Group (or through other organizations such as ACMLA). The sessions emphasize issues from the support staff perspective. The Map Library Assistants and the OCUL Map Group communicate regularly and participate in many of the same projects.

By the turn of the new millennium, as geospatial data collections grew in size and complexity, the OCUL Map Group began to discuss the merits of a shared technical infrastructure. Since the mid-1990s, Canada had been engaged in the creation of a Canadian Geospatial Data Infrastructure, which includes the goals of fostering geospatial data access and providing a foundation of framework data (Masser 2005, 37). Despite the lack of a formal mandate, the Canadian government did succeed in establishing a national data clearinghouse known as the GeoConnections Discovery Portal. However, within the provincial academic context, libraries were providing access to data that was not being made openly available via the national infrastructure, and there was a clear need for a provincial-level spatial data infrastructure that could improve geospatial data access within the academic community across the province.

The phrase spatial data infrastructure has been defined as "a framework of technologies, policies, and institutional arrangements that together facilitate the creation, exchange, and use of geospatial data and related information resources across an information-sharing community" (Esri 2010, 2). This is a very apt description of what the OCUL Map Group set out to do. They worked with Scholars Portal, OCUL's technical arm, to solve their shared storage and distribution challenges with the creation of a new service called Scholars GeoPortal, launched in 2012. Scholars GeoPortal is our second example project.

In 2013, OCUL underwent an organizational restructuring, and as part of this the OCUL Map Group became one of several "communities". ${ }^{3}$ Upon becoming a community, the group elected a new name, the OCUL Geo Community, to reflect the evolution in the role of the map librarian, who today works not just with map collections, but with all forms of geographic information, including digital maps and geospatial data. The OCUL Geo Community continues to provide a forum for the exchange of information and ideas pertaining to maps, geospatial data, and other cartographically related resources, both print and digital. The Geo Community today communicates somewhat differently than it did in the past. Budget cuts have meant fewer resources are now available for the group to meet in person, but a host of communication options exist today, such as wikis and conference calls, which allow the group to continue to pursue collaborative projects. The terms of reference have evolved with the times as well; today the Geo Community's objectives include:

1. Collaborating to provide a world-class learning experience for Ontario's students.

2. Expanding shared digital research infrastructure.

3. Providing and preserving academic resources essential for teaching, learning, and research.

4. Engaging in research and special projects. 
5. In the OCUL context, creating and maintaining partnerships with government and external agencies.

6. Monitoring changes/trends in geospatial technologies, research, and services e.g., open data initiatives, community mapping projects.

These are arguably a more ambitious set of objectives than the ones originally outlined in the 1970s. This reflects the confidence that the group, and OCUL as a whole, have gained from their successes. Community members will be embarking on a new project in 2015 , to digitize a major series of Canadian printed maps; this project is featured as our third collaborative example.

The three projects described in detail in this section have some commonalities. They all emerged from the discussions undertaken through the OCUL Map Group/Geo Community, emphasizing the great value to be gained from professional networking and educational experiences. The outcomes of each project have provided (or will provide) tangible benefits to each group member's institution; however all members are not expected to have the resources to contribute equally to the work of the project. Each library contributes what it can in terms of staff time, expertise, and/or funds in order to make a project happen and the results are shared with the entire group (or the world when possible). In addition, OCUL Map Group projects always evolve in consultation with external stakeholders, ranging from government entities, to the research community, to the library community outside Ontario.

In addition to their commonalities, there have been differences between the projects as well. While they all operated under the OCUL umbrella, each project relied upon the support structures OCUL provides to differing degrees. In the OCUL Map Group's early days, their activities were effectively independent from OCUL as an organization. Individual members shared information and worked on projects together as needs arose. With the development of the Scholars GeoPortal proposal, the scale of the project increased, and external funding was required. OCUL was able to facilitate the grant application process, provide a home (at Scholars Portal) for staff hired to develop the GeoPortal, and provide administrative support for the project. Since the OCUL restructuring in 2013, new processes have been put in place to facilitate communication between communities and the OCUL governance body, known as the OCUL Directors, ensuring that library staff have the means to raise awareness about emerging needs they have identified, and in some cases apply for central OCUL funds to undertake projects. This is how the Geo Community's new map digitization project emerged. While this new OCUL model introduces an expectation that map/GIS libraries will work on projects within a more formalized structure, it offers the advantage of allowing library directors to express their support by funding strategic projects from centrally allocated resources, rather than only through individual map/GIS library budgets.

The opportunities provided by collaboration through the OCUL Geo Community have ensured a greater capacity to manage evolving collections of geospatial data. The group serves as a community of practice, providing educational opportunities and facilitating collaborative problem solving. This collegial environment has also led to specific projects, creating new technical infrastructures and developing strategies for sharing the workload on data management tasks. Each of the three projects discussed in this section has played (or is playing) a significant role in improving the management, dissemination and preservation of geospatial data collections in Ontario. Each project's success was ensured through effective collaboration both within the OCUL Geo Community and with a range of stakeholders and partners. 


\section{Consortial license negotiation and acquisition: working together to establish core geospatial data collections in the early years of digital data}

The OCUL Map Group began actively pursuing consortial acquisitions in the 1980s, before the advent of digital geospatial data. At the Spring 1982 OCUL Map Group meeting, there was much discussion about establishing a depository arrangement with the mapping office at the Ontario Ministry of Natural Resources (OMNR) for their Ontario Basic Mapping (OBM) topographic printed map sheets at scales of 1:10,000 for southern Ontario and 1:20,000 for northern Ontario. It was agreed that the chair of the Map Group would call the OMNR program manager and follow up with a letter outlining the group's interest. By September, the manager had met with Map Group representatives and stated that he "was encouraged to learn that our OBM maps are in demand in the university environment and we agree that it would be very useful if copies of our maps are available for detailed perusal" (Jackson 1982). The Map Group divided the province into regions, so that each university would receive about 400 map sheets at a scale of 1:10,000, or 100 at 1:20,000. Free distribution of these maps began in January of 1983 and was completed by March. Thirteen university map collections participated in this depository agreement - Windsor, Western, Waterloo, Brock, McMaster, Guelph, Toronto, York, Trent, Queen's, Carleton, Ottawa and Laurentian. Maps were to be used for reference purposes only and could be made available to other Map Group members for ILL. If any sheets were wanted beyond the depository areas, maps could be purchased from OMNR at $\$ 2.00$ per sheet. Despite being published initially in black and white, these maps were popular with users because they provided more detail than any federally-produced topographic maps of the same area. 


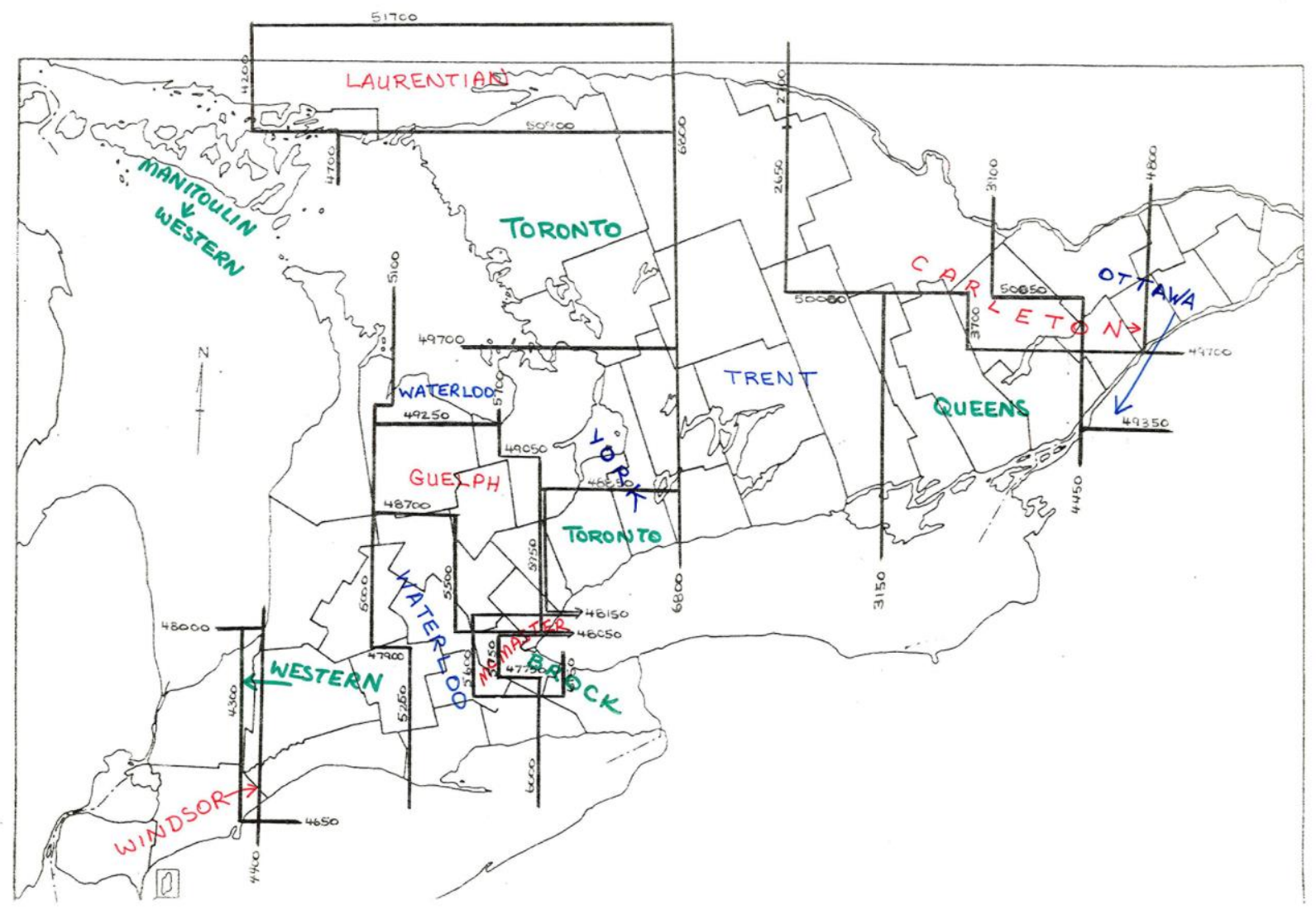

Figure 3. Map showing regions delineated for distribution of Ontario Basic Mapping (OBM) sheets to Ontario academic libraries. Created by the OCUL Map Group in 1982. Source: OCUL Map Group archives, Western University Libraries, Map and Data Centre.

During the 1990s, the attentions of the OCUL Map Group gradually shifted towards digital maps and geospatial data. In 1993, Map Group members formed the Digital Map Information Task Group, with the goal of writing a report that could be presented to library administrators to provide background information on the needs and directions of service delivery for digital geospatial data. The two primary sections dealt with the "role of the library in the provision of spatially referenced digital information" and "service considerations" (Farrell 1994, 1-9). These were subdivided into further sections detailing digital geospatial material, equipment, software, staff, and user training. This seven-member task group sparked interest within the OCUL Map Group to undertake an inventory of digital data held in each member's collection.

At the same time, some Map Group members were receiving development funding to purchase GIS workstations within their map libraries. Much discussion ensued about the specifications of the computer/printing/scanning equipment needed for these workstations and the software required to meet client requests sufficiently. ESRI Canada representatives gave a slide presentation on the functions and capabilities of ArcView 2 at the spring 1994 OCUL Map Group meeting. It was stressed that ArcView 2 was an improved product for end users because it was 'object oriented' - it related attribute data to complete geographical entities (which were 
understandable to people), rather than to arcs and polygons. It was suggested that users could become acquainted with ArcView use in an afternoon and that the learning curve was gentler because of the visual similarity to Windows. This was one of the Map Group's first exposures to GIS technology.

The University of Illinois at Urbana-Champaign hosted a conference called the 32nd Annual Clinic on Library Applications of Data Processing: GIS and Libraries-Patrons, Maps and Spatial Information, in the spring of 1995. Six OCUL Map Group members attended that conference and reported back to the Group about the impressive progress that some U.S. map libraries were making with implementing digital data. However, it was obvious that the U.S. had liberal access to information compared to the restrictive access to Canadian data. Overall, the experience of attending this conference further raised the interest and incentive of OCUL Map Group members to pursue more discussion and action.

In the spring of 1995, OMNR was ready to provide the OBM topographic maps in color and in a digital format. A five member Map Group Subcommittee was formed (the Subcommittee on Data Licence Agreements) to investigate and provide a report to the group about data licence agreements, with a focus on the draft end-user licence agreement written by OMNR for digital maps. The report was presented to the OCUL Directors in March 1996. The Subcommittee compiled feedback from all OCUL libraries and worked with OMNR to create an agreement specifically geared to the academic sector and intended for non-commercial use. These draft agreements were originally intended for all clients in the commercial and noncommercial sectors; however, changes in intellectual property legislation, and subsequent adjustment of OMNR policy, prompted the Subcommittee to explore alternative, more costfeasible licence options. Among the private and public sectors OBM maps were gradually being adopted as the standard outline maps against which to display themes of Ontario. As such, these digital maps were considered highly desirable for any GIS teaching curriculum and would no doubt become essential for many research projects. The Subcommittee identified three options for improving access to digital maps - depository agreements, consortia and partnerships. The concept of a consortium, with the understanding that it may require some level of financial support from all OCUL institutions, was the direction that was favored. Meetings were held with OMNR to discuss its digital licensing procedures, and OCUL Map Group members eventually agreed to sign a multiple end-user licence agreement. Through participation in meetings and the provision of draft agreements, OMNR demonstrated a willingness and interest in improving library access to digital maps.

In the late 1990s, OCUL Map Group members began to approach their local geospatial data providers for free vector and raster data that could be shared throughout OCUL for teaching and research purposes. Negotiations began for licenses to data layers produced by municipalities, including Hamilton, London and Ottawa. Agreements with the Grand River Conservation Authority and the Regional Municipality of Niagara soon followed. License agreements were signed and discs were distributed to each institutional map collection.

In 2001, the OCUL Map Group participated in a demo/training session by a local commercial geospatial data company - DMTI Spatial Inc. At that time DMTI was introducing a new product, a comprehensive street network database to be known as CanMap $\AA$. Immediately, there was a national interest in this product and additional GIS services being offered by DMTI. A consortial purchase was coordinated with leadership from the University of Toronto Map and Data Library. Over forty libraries from across Canada registered for a oneyear agreement, including many OCUL Map Group members. This consortium continues to be negotiated annually for what has come to be known as the Spatial Mapping Academic Research Tools (SMART) Program, with an optional agreement for Satellite Street View data. Since then, "the SMART Program has provided 90,000 students and faculty members access to Canadian Location Intelligence data in support of research, engineering, environmental and business studies" (DMTI Spatial 2012). 
Table 1. List of consortial licenses negotiated by members of the OCUL Map Group

\begin{tabular}{|l|l|}
\hline Consortial License & Date Negotiated \\
\hline $\begin{array}{l}\text { Ontario Basic Mapping (OBM) } \\
\text { topographic sheets (print) }\end{array}$ & 1982 \\
\hline OBM topographic sheets (digital) & 1996 \\
\hline Various municipalities & Throughout the late 1990s \\
\hline $\begin{array}{l}\text { DMTI Spatial Inc. (national } \\
\text { SMART Consortium) }\end{array}$ & 2001 \\
\hline Ontario Parcel Database & 2003 \\
\hline $\begin{array}{l}\text { Ontario Geospatial data Exchange } \\
\text { (OGDE) }\end{array}$ & 2003 \\
\hline
\end{tabular}

Table 1. Examples of consortial licenses negotiated by members of the OCUL Map Group

More consortial agreements followed. The Ontario Parcel Database was established in 2002, resulting from an agreement between OMNR, the Municipal Property Assessment Corporation (MPAC) and Teranet Enterprises Inc. The agreement was to "gather information about Ontario's estimated four million land parcels and bring this knowledge together into a standardized digital database" (Teranet Enterprises). OCUL Map Group members expressed an interest in this database, and talks began with Teranet. An educational agreement between the University of Toronto and Teranet was completed in 2003, with the University of Toronto providing data distribution to the participating institutions through a sublicensing arrangement with Teranet. This was a three-year agreement and has been renegotiated periodically since then.

By 2003, the OCUL Map group was working on negotiating membership in the Ontario Geospatial Data Exchange (OGDE), which would give libraries at Ontario universities and colleges access to a range of georeferenced land information data produced by provincial ministries. The OGDE, a concept introduced by the OMNR Land Information Ontario (LIO) project, provided for the centralized deposit and sharing of geospatial data within Ontario's broader public sector through a standard license agreement, a data directory, and a distribution facility (known as the LIO Warehouse). As the largest producer of geospatial data in the province, OMNR had been appointed by the Ontario Management Board of Cabinet to serve as the "lead" ministry to coordinate the OGDE initiative.

As part of its mandate, OMNR negotiated with the public, private and academic sectors regarding their possible membership in the OGDE. OCUL map libraries had made several earlier attempts to acquire land information data for their clients. In the previous two years, six Map Group member universities had signed Memoranda of Understanding (MOU) with OMNR to receive data sets from the Ministry's principal database - Natural Resources and Values Information Systems (NRVIS). These MOU agreements were intended to serve as short-term contracts, which filled the gap until OCUL joined the OGDE. Clauses in the MOUs stipulated 
that once the OGDE had been formalized, the data transferred under the MOU agreement would become subject to the terms and conditions as defined by the OGDE agreement. The OCUL Map Group Geospatial Data Committee was instrumental in formulating the proposal for the OGDE agreement. A part of the negotiation of the OGDE agreement was to clarify that universities would be members who were not expected to actually "exchange" or provide data to the OGDE.

The LIO Warehouse was principally populated by OMNR data, with approximately 114 layers of Ontario land information data produced at large scale. OMNR estimated that this represented approximately $30-35$ GB of data. The Warehouse would serve as the main clearinghouse for all provincial land information data. Initial contributors in addition to OMNR were: The Ontario Ministry of Environment, the Ontario Ministry of Northern Development and Mines, and the Ontario Ministry of Transportation.

A letter of understanding was signed between OMNR and OCUL, which provided Map Group institutions with a three-year payable fee. Each OCUL Map Group institution signed an OGDE license agreement between OMNR and their institution. As a result, each Map Group member was given a password to access the LIO Warehouse and download files for their users. Some Map Group members also chose to store this geospatial data locally and a hard drive was circulated to institutions that requested it from OMNR. The content of that hard drive was copied to a local server and discs were burned with the downloaded files and supplied to the user. At some institutions, access to geospatial data files was made available through IP address authentication.

In the course of pursuing consortial licensing from the 1980s to the present, the OCUL Map Group has learned that there are a number of potential barriers to acquisition, which can present challenges either to achieving consensus around the need for a license, or to negotiating the license itself. Throughout this period, both map libraries and their parent organizations have experienced significant organizational change. Acquisitions practices, staff roles, and (perhaps most importantly) budgets vary widely from institution to institution within Ontario. Libraries have had to take a leadership role within their institutions in order to communicate the role of the library with respect to geospatial data to ensure that the academic community is aware of these services and that researchers do not separately acquire data already available from the library (Pinnell 2000, 17). In Ontario, without this clarity of the map/GIS library's important role within the academic institution, achieving sufficient commitment for consortial license negotiations would have been challenging.

The OCUL Map Group has necessarily had to strike a fine balance between individual and consortial needs in order to make headway towards big consortial licensing goals. In each case it has been necessary for one or a small group (subcommittee) of individuals within the group to step forward and take the lead on a particular negotiation. These individuals may have a strong organizational need for that specific product, which drives them to dedicate what is typically an extensive amount of time to achieving a license negotiation on behalf of the group. In practice the University of Toronto, as Canada's largest university, has often played a substantial role in facilitating consortial negotiations, liaising with data producers, and providing data storage space that OCUL institutions can access. At the same time, without demand from all participating members a consortial license is not possible. For this reason, not all discussions about data and software products have led to consortial licenses. In some situations, the group recognized that the needs of the members were too varied and that it would make more sense for individual institutions to assess their local research needs and make their own decisions about acquisition. A good example of this is the case of digital orthoimagery. Because user demand tends to be for the areas immediately surrounding the local institution, and because orthoimagery is extremely storage intensive, institutions are most strongly interested in coverage for specific local areas, making a provincial license unrealistic. The OCUL Map Group continues to seek out and pursue potential consortial licenses today, recognizing the need for 
flexibility in the decision-making process about which products would provide the most value and have the highest likelihood of successful negotiation.

\section{The Scholars GeoPortal project: shared infrastructure for geospatial data storage and dissemination}

Because of the consortial negotiations undertaken by the OCUL Map Group, geospatial data collections in Ontario libraries grew rapidly, and as GIS technologies improved the size of datasets increased exponentially. For most OCUL member libraries, sustaining the capacity to store and distribute the data to users became a challenge - one that was naturally an important topic of discussion at OCUL Map Group meetings. The discussions crystallized into a plan, which resulted in writing a proposal for submission to OCUL requesting funding for the development of a centralized geospatial data storage and delivery system, intended to house consortially licensed geospatial datasets. A draft proposal was completed and submitted to OCUL in April 2008.

The vision for the project was to create a centralized system for geospatial data storage, description and access (essentially, a spatial data infrastructure for Ontario libraries), intended to house consortially licensed geospatial datasets. By housing the data centrally at Scholars Portal, libraries would increase their collections and data management capacity without requiring large amounts of storage space at each individual library. Similarly, certain data management, metadata, and data distribution tasks could also be centralized at Scholars Portal, freeing up staff time at member institutions to focus on more important public service roles, such as reference and teaching. Finally, by including an online geospatial portal with search, preview, query, download and sharing functionality, this system would provide new tools for users that few member libraries could provide on their own. At that time most Ontario libraries did not offer any online system for discovery and download of their data collections, users would need to physically visit the library and have the data transferred to a DVD or thumb drive. The functionality envisioned for this new system would represent a great step forward in improving awareness of and access to geospatial data for Ontario's researchers and students.

The OCUL Directors were supportive of the ideas expressed in the proposal, and requested that the scope be broadened beyond that of a shared data infrastructure, to include innovative concepts about the use of geospatial data as an educational tool within an online environment. At that time most existing geospatial portals had been built by the government, and it was felt that there was significant opportunity to leverage new technologies to build a tool more suited to the educational environment. In response, the OCUL Map Group hosted a Geovisioning Workshop bringing together approximately 40 researchers, librarians, and data specialists from participating OCUL institutions in October 2008 at Ryerson University. The workshop provided an opportunity to share knowledge among scholars working with GIS, and build on the vision documented in the initial proposal. The exercise generated a list of ideas for the necessary components in a cutting-edge system that would support research across disciplines (including subject areas outside of conventional GIS and geomatics), and to serve a range of users from novice to advanced. These focused on features that would support educational goals and facilitate the acquisition of geospatial literacy skills. The recommendations included the provision of sophisticated search-and-download functionality (including geographic search, clip-and-ship downloads, and choice of a range of file formats and geospatial reference systems), in-depth metadata and data exploration options to support assessment and comparison of available resources, and the provision of extensive help materials to ensure users could make sense of GIS vocabulary. An inventory of then-cutting edge, "Web 2.0" geospatial data tools conducted by EDINA at the University of Edinburgh provided a number of inspiring illustrations of the functionality described by Geo-visioning 
Workshop participants (Macdonald 2008). These ideas formed the core of the GeoPortal's functional requirements, which guided the development project.

At this stage, collaboration became vital on several levels. Not only was it necessary for OCUL Map Group members to work together to envision what was needed and put it into writing, but for the project to move forward OCUL needed to make a financial commitment, with the knowledge that a relatively modest contribution from each partnering library could reap significant benefits in future cost savings and improved service offerings. In addition to financial commitment, technical capacity was needed, which fortunately was already available in the form of Scholars Portal. Scholars Portal already managed OCUL's technical infrastructure for the storage of digital information resources, and had a history of developing user interfaces for discovery and access of these resources. As a result, this project would build upon earlier OCUL-wide collaborative projects.

Following the Geo-visioning Workshop, OCUL put its support behind the enhanced proposal, and began to look for external funding opportunities in order to make it a reality. The right opportunity came along via the Government of Ontario's OntarioBuys program. A business case for the project was developed and submitted, proposing the creation of a geospatial data portal through a combination of government and OCUL funds. In March 2009, OCUL was awarded the project grant.

In order to accomplish the work of the project, a number of working groups were formed, with members drawn from the OCUL Map Group, as well as staff at Scholars Portal and OCUL institutions. Working groups included a Project Management Group, a Technical Standards and Collections Working Group, a Teaching and Learning Working Group, a Health Data Collections Working Group, and an External Advisory Committee. ${ }^{4}$ Each group had a formal mandate, a series of milestones, and key tasks that drove the collaborative effort. For example, the Technical Standards and Collections Working Group compiled the list of functional requirements, evaluated potential software vendors, selected a metadata standard, developed metadata best practices, and prioritized data collections for loading into the portal. Several staff were hired at Scholars Portal to set up the data storage infrastructure, design and develop the portal user interface, and to perform the data loading and metadata management tasks. Representatives from Scholars Portal joined the working groups to ensure that the community had input into the technical implementation throughout the project.

Working groups on the Scholars GeoPortal project were extremely engaged, active, and productive. In order to allow individuals from across the province to participate, the majority of meetings took place via conference call, and notes and documents were collected in a wiki. Throughout the three-year project, most working groups met almost weekly, with many tasks completed between meetings. More than thirty individuals from nearly all of OCUL's twenty-one libraries had a hand in the development of Scholars GeoPortal through participation on working groups. These participants all required the formal support of their library directors in order to undertake such a large time commitment above and beyond their regular job responsibilities. Ontario's library directors showed a great deal of support for the Scholars GeoPortal project throughout.

As the development of the portal neared completion, the working groups prepared for its official release by extensively testing the beta version, and by preparing promotional and instructional resources, ranging from handouts to step-by-step tutorials. ${ }^{5}$ Scholars GeoPortal officially launched on March 1, 2012 and received the 2012 OLITA Award for Technological Innovation. ${ }^{6}$ That success represented the work of a great many individuals coming together to reach a shared goal. 


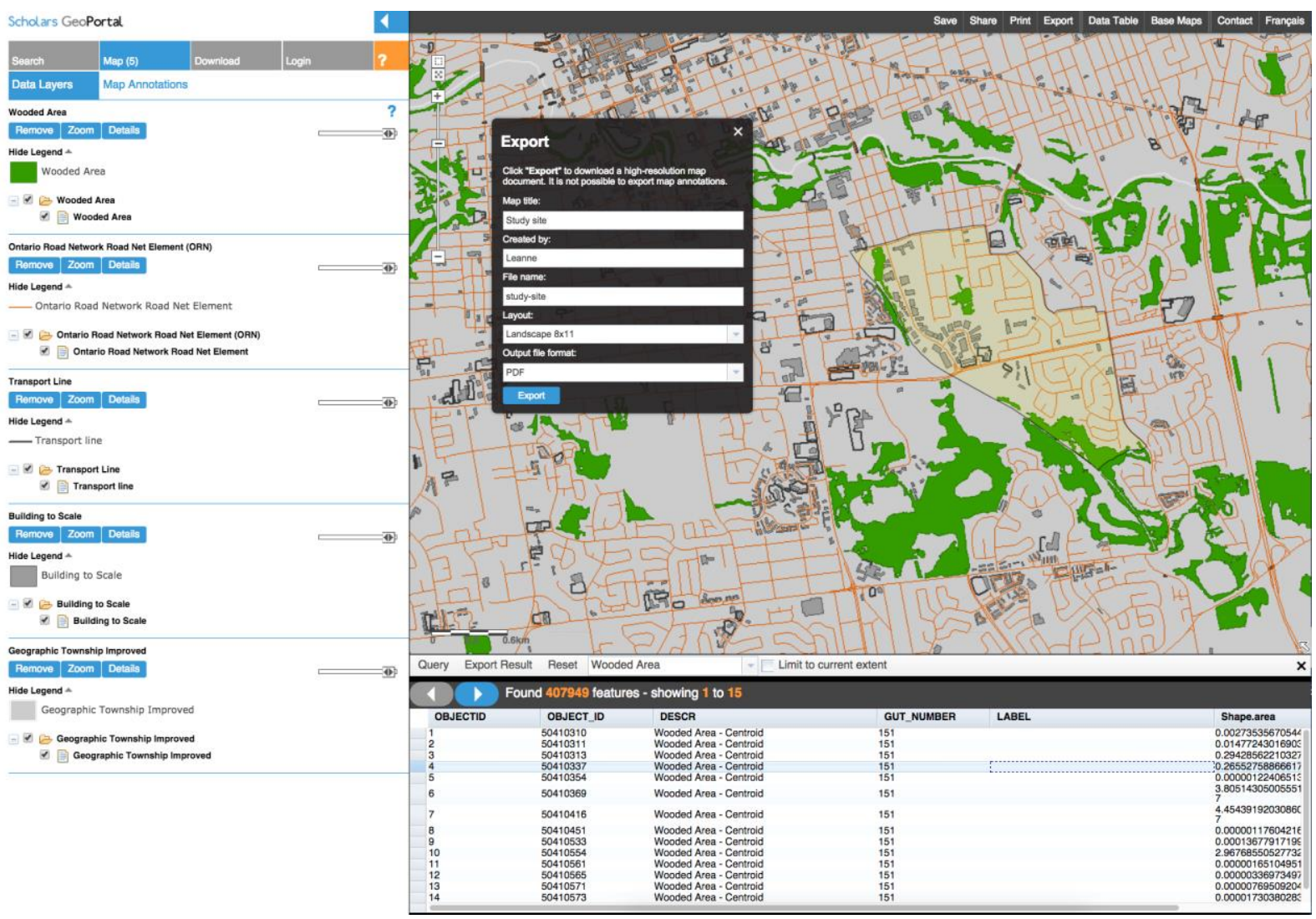

Figure 4. Screenshot of Scholars GeoPortal, showing display of map layers, view of attribute table, and selection of geographic location for downloading. Displayed on the map are data layers available to Ontario universities via the Ontario Geospatial Data Exchange.

As of January 1, 2015, the infrastructure housed approximately 800 geospatial datasets acquired from data providers such as DMTI Spatial Inc., OMNR, Statistics Canada, Ontario Ministry of Health and Long-Term Care, and Natural Resources Canada. In addition, select OCUL institutions have created and loaded metadata records and/or datasets representing their local, institution-specific collections - the ultimate goal being a single state of the art geospatial data search, access, and delivery tool (where data licensing permits).

Scholars GeoPortal continues to be a collaborative effort. It has become a core Scholars Portal service and the OCUL Directors have committed ongoing financial support to maintain the technical infrastructure, and Scholars Portal staff necessary to complement a sustained service. While the project working groups and weekly conference calls are now a thing of the past, the members of the OCUL Map Group (Geo Community) continue to participate in supporting the service. On their bi-monthly conference calls, the group hears updates from Scholars Portal staff, and provides input into data loading priorities and new features being developed. Scholars GeoPortal user support is also a collaborative effort. Questions submitted by Scholars GeoPortal users go to a community email list where librarians from a number of OCUL institutions can view them. Scholars Portal staff provide the first line of support, answering primarily technical questions about the use of the GeoPortal. When questions have a reference component, OCUL librarians can contribute their expertise to help respond to the user. 
These practices were intentionally designed to ensure that OCUL GIS and Map librarians remain actively involved with the service they helped to create. The group feels strongly that this is the best way to ensure that Scholars GeoPortal continues to evolve in the direction that will best meet the needs of users. There is no doubt that Scholars GeoPortal will evolve. Since the project began, many changes in the technical and information landscape have occurred. The increasing presence of open data portals at the federal, provincial and municipal level demonstrates that attitudes on data licensing are changing, which may have an impact on decisions about the content to be served through Scholars GeoPortal. Web GIS technology is also evolving rapidly, bringing with it new opportunities for web mapping interfaces like the GeoPortal. Scholars Portal staff and OCUL libraries will continue to contribute their knowledge towards solving new problems and meeting evolving needs for Scholars GeoPortal.

\section{Preservation of historic collections: map digitization and georeferencing projects}

OCUL Map Group members have collaborated on several digitization and georeferencing projects over the years. This work has included sharing scanning specifications and georeferencing techniques, group funding for multi-institution projects, and a push to disseminate the outputs of these projects on platforms such as Scholars GeoPortal, ArcGIS Online, and Google Earth.

\section{Air photo digitization}

Air photos provide a valuable snapshot in time for researchers interested in changing landscapes and urban development. Many OCUL universities collect these photographs, and have experienced a growing demand for digitized and georeferenced images in recent years. One of the earliest comprehensive air photo digitization projects undertaken by a Map Group member began at Brock University in St. Catharines in 2005. A set of approximately 1500 air photos of the Niagara region from 1934 were scanned, mosaicked together, georeferenced, and integrated into Google Earth's database of historical imagery (Beard 2014, 28). Brock University staff have gone on to initiate a number of additional air photo projects, most notably the digitization and mosaicking of public domain photos from multiple years, accompanied by digitized flight line indexes in ArcGIS Online. ${ }^{7}$ Brock's open approach to these projects, including sharing their data and documentation online, has allowed other institutions to benefit from their experiences.

Several other OCUL institutions have embarked on air photo digitization projects in recent years. Geo Community members regularly share specifications and techniques, and it has become common practice for public domain materials to be made accessible online. Recent projects in this vein include the University of Waterloo's 2007 initiative to scan approximately 2000 historical air photos of Kitchener-Waterloo and surrounding areas dating from 1930 to 1963. The University of Western Ontario has scanned approximately 1000 historical air photos of London, Ontario dating from 1922 to 1964. At Trent University in Peterborough, over 10,000 air photos, from 1928 to the early 1980s, have been georeferenced and made available to the Trent community and the public, copyright permitting. 


\section{Historical map digitization}

Researchers, students, and the general public regularly use historical topographic maps to conduct change-over-time comparisons. Access to these maps promotes new methods of analysis and affords the exploration and referencing of important Canadian time series data. While many of these historic topographic maps are in the public domain, the federal government has no current digitization plans for older series and only the most recent versions are available online through the Government of Canada. The digitization of these maps removes access barriers, improves resource discovery, and provides a long-term preservation solution to the challenges of maintaining often-incomplete sets of these maps during ongoing cutbacks.

Previous digitization initiatives have included Brock's digitized historical topographic maps of the Niagara region, as well as McMaster's collection of scanned trench-warfare maps and WWII-era topographic maps of Europe produced by the British War Office, Geographical Section, General Staff (G.S.G.S.) and the U.S. Army Map Service (A.M.S.) produced between 1939 and 1945. Staff at the University of Western Ontario (UWO) in London have scanned and made available four fire insurance plans for the City of London dating between 1888 and 1922. The UWO team have also scanned the first detailed topographic map of the city, produced by the Geodetic Survey of Canada in 1926.

\section{Vectorization of historical map data}

While the scanning and georeferencing of maps and air photos is a valuable practice in and of itself, it can also be useful to create layers of vector data to represent historical information in a GIS context. These derived datasets are beneficial for creating digital maps of historical attributes, and can also help researchers identify and apply modern GIS techniques to previously analogue data sources like maps and air photos.

One example of this kind of project was initiated at Trent University, whose library staff is working with researchers and students to build a collaborative Regional Environmental History Atlas of South Central Ontario. ${ }^{8}$ As part of the project, the locations of over 300 historic mills were mapped using GIS software, allowing researchers to understand settlement patterns and the growth of industry in the region.

The Don Valley Historical Mapping Project, by Jennifer Bonnell (Professor of History, now at McMaster University), and University of Toronto GIS and Map librarian Marcel Fortin, also exemplifies this approach. ${ }^{9}$ Hundreds of georeferenced maps and fire insurance plans were first scanned. Vector data were then created from the scans. These included shoreline and river changes, industries, animal processing facilities, breweries and distilleries, lost waterways, and land ownership information.

\section{Consortial digitization initiatives}

The various digitization, georeferencing, and vectorization projects conducted by individual Ontario universities have led to the development of a great deal of expertise around these activities. Libraries have a history of sharing not only the digitized, out-of-copyright resources, but also their guidelines and procedures. The time has come to utilize this expertise to accomplish similar projects together, realizing the potential of the combined historic collections of all libraries in the province.

In late 2014, OCUL approved funding to digitize historical topographic maps (at 1:63,360 and 1:25,000 scales, produced by Department of Militia and Defence; Department of National 
Defence; Department of Mines and Technical Surveys; and Department of Energy, Mines and Resources) located in the collections of member institutions. This project will expand upon an existing project initiated at the University of Ottawa in 2013. The project aims to add approximately 800 maps to the consortium's collective holdings over three fiscal years. The funds will permit the Geo Community to hire staff at a number of OCUL libraries to conduct digitization and georeferencing of historical topographic maps, as well as to develop best practices for including these and other digitized map collections in Scholars GeoPortal. The project will allow more OCUL institutions to become involved in digitization activities. Those institutions with existing scanning equipment will take on the scanning tasks, but other institutions will have the opportunity to participate in tasks such as metadata creation and georeferencing. This project will enhance the province's digital collections, provide learning opportunities for member institutions, and establish best practices for future projects to digitize Canada's historic topographic maps, both within and outside Ontario.

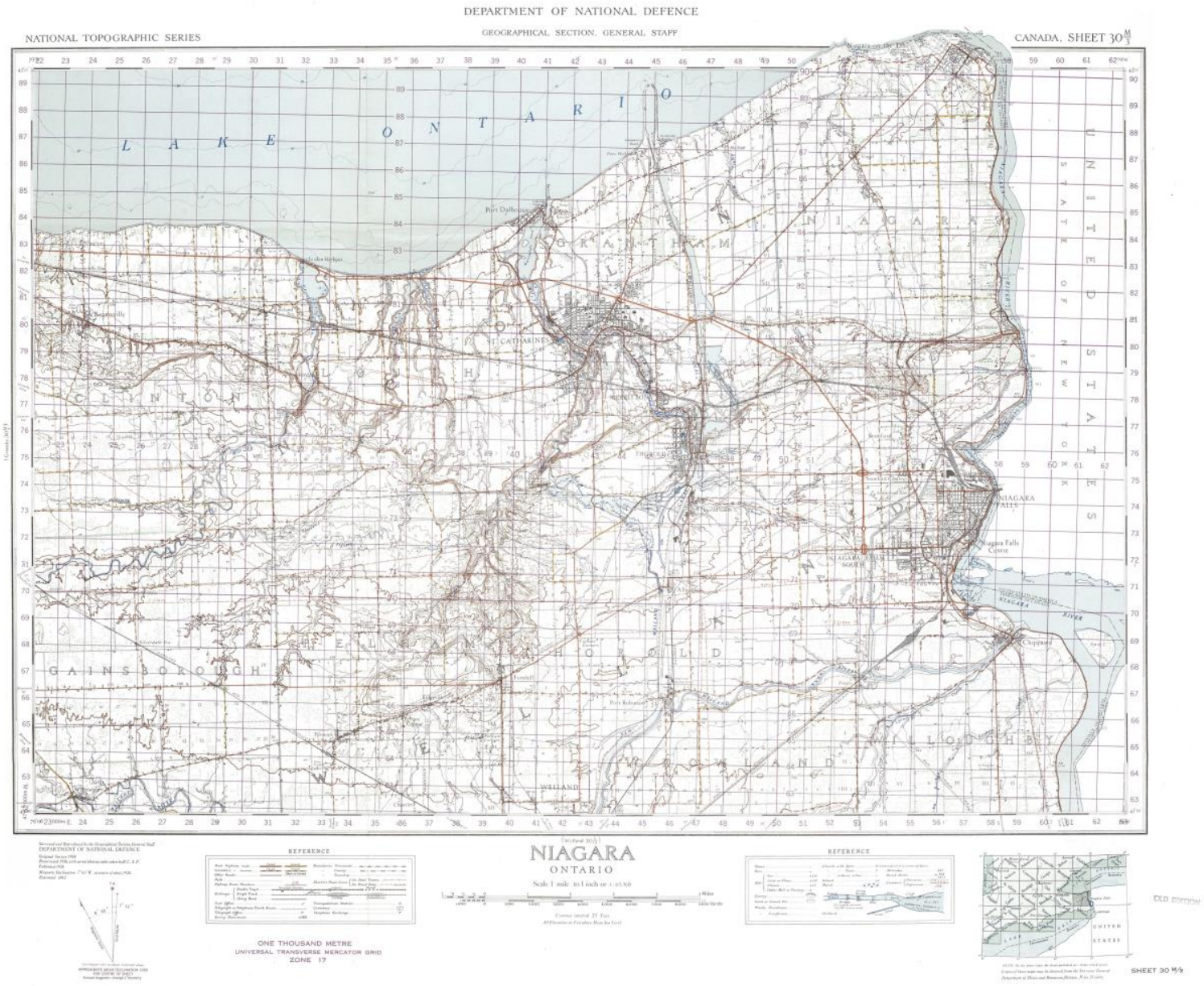

Figure 5. Topographic map of Niagara, Ontario, published by the Department of National Defence in 1938. This map is a part of the OCUL Geo Community's historical map digitization project 


\section{The Ingredients for Successful Collaborations}

Since the OCUL Geo Community has been collaborating for over forty years, the projects described in this paper represent milestones in an ongoing journey. Time has taught the OCUL Geo Community that collaboration begets collaboration - one successful collaborative project inspires future collaborations, and daunting projects can seem more feasible after establishing and developing a history of working together. The co-authoring of this article by five members of the Geo Community from different organizations across the province, made possible through a simple summoning via listserv, demonstrates the snowballing effect of collaboration. Of course, no collaboration is without its challenges. It takes trial and error to learn the many skills needed for success: choosing the most strategically impactful projects, establishing a governance and communications model, and assigning roles and deliverables effectively are not straightforward tasks. Many years of experience have left the Geo Community with some insights into the nature of successful collaborations.

\section{Develop a support network}

For those without the benefit of an existing group like the OCUL Map Group/Geo Community, finding a few partners for a very small project can be a great way to start, as it may lead to bigger things later. That said, finding a place for a project within an existing collaborative infrastructure can be a great boon. The Geo Community's establishment within a larger organization like OCUL that is already committed to collaboration was an obvious choice and has positively influenced its staying power. Working within the OCUL framework affords the Geo Community access to expertise about consortial data licensing, as well as the use of the infrastructure at Scholars Portal. In addition, the OCUL Directors show commitment to map and data services by supporting their staff in dedicating time to Geo Community projects. Each project typically needs a few individuals to provide leadership and oversight, and these people may need to devote a large amount of time to these activities for a certain period. This has been particularly effective when combined with technical project management from staff at Scholars Portal. Relying on support and infrastructure at OCUL/Scholars Portal and the collective expertise of the Geo Community enabled the collaborative development of the Scholars GeoPortal.

\section{Recognize your vested interests}

In any project, each potential collaborator needs to understand their vested interest, as well as that of all the other collaborators (Guard 2005). Collaboration cannot be successful if all parties' best interests are not satisfied in the long term. This need not be thought of as a selfish way of approaching collaboration. Guard provides an excellent example in the various University of Cincinnati library systems participation in OhioLINK for collection licensing. Sometimes a collaborator will agree to purchase "out of scope" resources because "their vested interest analysis dictates that what is good for the university as a whole is ultimately and strategically good for each library venue" (Guard 2005, 90). Not unlike OhioLINK, many of OCUL's projects are designed for the good of the consortium.

Decisions made for the greater good of the consortium benefit each member institution differently. For example, what the OCUL Geo Community collectively purchases and the order in which data is loaded into Scholars GeoPortal must be prioritized. Data might be loaded first to fill collection gaps or to fulfill the research needs of users, influencing the representation of 
some geographical areas more than others. Addressing the disparity in service across Ontario universities is in the vested interest of the consortia as well as each library member. Relying on a vested interest makes for a complex and multidimensional relationship that evolves and changes over time as technology develops, budgets shift, as more data becomes available and as researchers explore geospatial information using new methods.

\section{Establish Trust}

The Geo Community's long history is an important contribution to the group's success, since "collaboration also works best when built on personal relationships" (Helmer 2012, 183). Forty years has given the Geo Community a lot of time to establish the personal relationships required to support professional collaborations. Opportunities like association membership and project work have provided additional opportunities to develop these relationships within the profession, helping to develop the trust needed to work through different challenges. Inevitably with complex collaborative projects, there will be aspects that are beyond any one participant's skill set. Those involved need to be able to trust others who do have those skills sets and have "mutual trust that everyone involved will accomplish their assigned tasks" (Clement 2008, 194). Trust enables participants to sacrifice some control and share in the risk that is intrinsic to all collaborations (Antelman and Couts 2009). For the Ontario historical topographic map digitization project, different institutions will be taking on different roles in the project (digitization, georeferencing) and working independently according to a set of best practices determined by group consensus. The group as a whole trusts the expertise of each institution as they complete their role in the project (though of course, some quality checking will also occur!).

\section{Encourage Flexibility}

Member institutions of the OCUL Geo Community each support a unique variety of academic disciplines and operate under different staffing models and budgetary limitations. As a result, flexibility is mandatory if collaborative efforts are undertaken to investigate consortial licenses that can benefit all institutions. Such investigations have had varying levels of success in recent years due to administrative policy and existing licensing agreements/pricing models in place between software vendors/data creators and the individual institutions. Results from unsuccessful negotiations represent valuable lessons that can be applied to future investigations. For example, in a recent negotiation for a web-based data product, it was clear that the level of interest was not consistently high across all OCUL Geo Community members. The community was able to find a flexible solution by negotiating a scalable pricing model. All institutions interested in joining the consortial deal can receive discounted pricing; if more institutions eventually join, all will receive larger discounts.

\section{Develop a robust communication network}

Coordinating many individuals in any circumstance can be difficult, especially when dispersed over a large geographical area, communicating through biannual in-person meetings and bimonthly conference calls. Timely decision-making and successful achievement of milestones is impressive when ground-breaking decisions are being made over conference call. During the development of the Scholars GeoPortal, no one in the group had previous experience with a large-scale web GIS development, meaning the project relied heavily on the collective expertise 
of the group and the establishment of working groups to fill the group's knowledge gaps. Communication is extremely important when embarking on a project where no one individual has all the needed expertise.

The group employed several tools and platforms to overcome distance and communications challenges, including a wiki collaboration space, conference call line, listservs, email and biannual in-person meetings. These platforms, as well as the creation of sub-committees, created the communications framework required for making decisions and meeting goals according to a planned schedule.

\section{Conclusion}

The OCUL Geo Community's mutual goals of expanding a shared digital research infrastructure as well as providing and preserving the academic resources essential for teaching, learning, and research have led to many successful collaborative projects. The group has been able to realize projects that would not have been possible without mutually motivating goals and challenges. A prime example of collaborative thinking is the persistence of the Geo Community despite the shifting vested interests of different libraries. Yesterday it was ILL, then it was the GeoPortal, now the group is coming together to protect and promote significant government information resources like historical air photos and topographic maps through comprehensive digitization projects hosted in the Scholars GeoPortal. The OCUL Geo Community has no intention of stopping at this stage. The group will continue to evolve and grow, but remains committed to working together to preserve and provide access to significant Canadian resources that can be used for a variety of purposes, inspiring the education of an informed citizenry for generations to come.

\section{Notes}

${ }^{1} \mathrm{~A}$ brief history of OCUL activities is available on the OCUL website (http://ocul.on.ca/node/25), as is an overview of all Scholars Portal services (http://ocul.on.ca/node/135).

${ }^{2}$ For more information on the OCUL Collaborative Future project:

http://ocul.on.ca/projects/collaborative-futures

${ }^{3}$ For more information on OCUL communities: http://www.ocul.on.ca/node/2163

${ }^{4}$ For a more comprehensive description of the project, including detail about the underlying technical infrastructure and functionality, see Hill and Trimble's article, listed in the Further Reading section.

5 These resources are available on the Scholars GeoPortal LibGuide:

http://guides.scholarsportal.info/geoportal

${ }^{6}$ For more information on the OLITA Technical Innovation award:

http://www.ocul.on.ca/node/553

${ }^{7}$ Brock University's historical air photos can be viewed in ArcGIS Online at http://www.arcgis.com/home/item.html?id=cbc8d1e8716549c788b138f83b7dd3f8

${ }^{8}$ For more information about the Regional Environment History Atlas of South Central

Ontario: http://www.trentu.ca/library/madgic/reha.htm

${ }_{9}$ For more information about the Don Valley Historical Mapping Project: http://maps.library.utoronto.ca/dvhmp/ 


\section{References}

Antelman, K., and M. Couts. 2009. Embracing ambiguity...or not: What the Triangle Research Libraries Network learned about collaboration. College \& Research Libraries News 70(4): 230-33.

Beard, C. 2014. Mapping the Welland Canals and the St. Lawrence Seaway with Google Earth. In Historical GIS research in Canada, ed. M. Fortin and J. Bonnell, 27-42. Calgary: University of Calgary Press.

Clement, S. 2008. Skills for effective participation in consortia: Preparing for collaborating and collaboration. Collection Management 32(1-2): 191-204.

DMTI Spatial. 2012. Press release: DMTI Spatial celebrates ten years of support to Canadian academia with SMART program.

http://www.dmtispatial.com/News/Press-Releases/SMART-Program.html

Esri Inc. 2010. Spatial data infrastructure: A collaborative network. Promotional brochure. http://www.esri.com/library/brochures/pdfs/spatial-data-infrastructure.pdf.

Farrell, B. 1994. Digital cartographic information in the map library. ACMLA Bulletin 91: 1-9.

Gajda, R. 2004. Utilizing collaboration theory to evaluate strategic alliances. American Journal of Evaluation 25(1): 65-77.

Guard, R. 2005. Musings on collaboration and vested interest. Journal of Academic Librarianship 31(2): 89-91.

Helmer, J. et al. 2012. Innovation through collaboration - the Orbis Cascade Alliance shared library management services experience: An interview with John F. Helmer. Collaborative Librarianship 4(4): 183-185.

Jackson, B. July 7, 1982. Letter to OCUL Map Group chair. From the OCUL Map Group uncatalogued archives, currently housed at Western University Libraries, Map and Data Centre. Contact Cheryl Woods for more information.

Kaufman, P. 2012. Let's get cozy: Evolving collaborations in the 21st century. Journal of Library Administration 52: 53-69.

Macdonald, S. 2008. Data visualisation tools: Part 2 - spatial data in a web 2.0 environment and beyond. JISC. http://www.disc-uk.org/docs/spatial data mashup V2.pdf.

Masser, I. 2005. GIS worlds: Creating spatial data infrastructures. Redlands: ESRI Press.

Millea, N. 2001. Organizational change. In The map library in the new millennium, ed. R.B. Parry and C.R. Perkins, 28-42. London: Library Association Publishing. 
Nfila, R.B., and D. Kwasi. 2002. Developments in academic library consortia from the 1960s through to 2000: A review of the literature. Library Management 23(45): 203-212.

Online Computer Library Center (OCLC). 2013. A snapshot of priorities and perspectives: U.S. library consortia. OCLC. https://oclc.org/reports/us-consortia.en.html

Pinnell, R.H. 2000. Data acquisitions issues: The Canadian map libraries' perspective. $A C M L A$ Bulletin 107: 16-22.

Ristow, W.W. 1980. The emergence of maps in libraries. Hamden, Conn.: Linnet Books.

Teranet Enterprises. n.d. Overview. Ontario Parcel website. http://www.ontarioparcel.ca/english/index.htm

Wallis, H. 1979. Map librarianship comes of age. In The Map Librarian in the modern world: essays in honour of Walter W. Ristow, ed. H. Wallis and L. Zögner, 107-116. Munich: K.G. Saur.

Weimer, K.H. 2011. The founding of ALA's Map and Geography Round Table: Looking back to see the future. MAGIRT Electronic Publication Series no. 11.

http://www.ala.org/magirt/sites/ala.org.magirt/files/content/Weimer MAGERT Founding.pdf

\section{Further Readings}

Hill, E., and L. Trimble. 2012. Scholars GeoPortal: A new platform for geospatial data discovery, exploration and access in Ontario universities. IASSIST Quarterly 6: 6-15. 